\title{
Social Relationships and Ritualized Greetings in Adult Male Baboons (Papio cynocephalus anubis)
}

\author{
Barbara B. Smuts ${ }^{1}$ and John M. Watanabe ${ }^{2}$
}

Received November 29, 1988; revised May 25, 1989

Greetings involving exchanges of ritualized sexual gestures are a common form of interaction among adult male baboons, although relatively little attention has been paid to them. In this study, we investigate how greetings reflect important aspects of the male's social relationships, including dominance rank, age/residence status, and cooperative tendencies. The results are based on over 600 greetings among 12 adult males recorded during a 4-month study of a troop of wild olive baboons near Gilgil, Kenya. Four of the adult males were older, lower-ranking, long-term residents, which frequently formed coalitions to take estrous females away from the eight young, higher-ranking males. Virtually all dyads greeted: greetings occurred more than twice as often as other types of male-male interactions; and nearly all greetings occurred in a neutral context, in which there was no resource at stake. The percentage of greetings completed, the frequency with which different gestures were employed, and the roles adopted by each male varied significantly across old-old, old-young, and young-young dyads. Greetings between young adult males were often interrupted or actively resisted, consistent with their unstable and ambiguous dominance relationships. Greetings between old-old dyads were usually completed and appeared consistent with their cooperative relationships. One pair of old males formed a stable, reciprocal coalition against young males, and this pair's greetings showed remarkable symmetry of roles. Greetings, we hypothesize, function to allow

\footnotetext{
'Department of Psychology and Department of Anthropology, University of Michigan, 580 Union Drive, Ann Arbor, Michigan 48109-1346.

${ }^{2}$ Department of Anthropology, Dartmouth College, Hanover, New Hampshire 03755.
} 
males to negotiate important aspects of their relationships, including cooperation.

KEY WORDS: baboons; greetings; coalitions; cooperation.

\section{INTRODUCTION}

Male baboons frequently engage in gestural exchanges involving ritualized sexual acts, such as posterior presenting, mounting, and genital touching. Such "greetings," as we will call them here, have been described for wild Papio cynocephalus anubis (DeVore, 1962; Ransom, 1981), wild P. c. cynocephalus (Altmann and Altmann, 1970), wild P. c. ursinus (Saayman, 1971), wild $P$. c. anubis-P. hamadryas hybrids (Sugawara, 1979), captive $P$. c. cynocephalus, $P$. hamadryas, and their hybrids (Pelaez, 1982), and captive $P$. c. papio (Anthoney, 1968, 1975). Hausfater and Takacs (1987) discuss one component of greeting, posterior presents, among wild $P$. c. cynocephalus; and Kummer (1968) and Abegglen (1984) describe a variant of greeting called "notifying behavior" among male $P$. hamadryas.

These greetings contrast sharply with other aspects of baboon male-male relationships. Indeed, greetings constitute the only context in which adult males routinely exchange friendly behaviors. Outside the context of greeting, male baboons generally interact in extremely tense and highly competitive ways (e.g., Hausfater, 1975; Packer, 1979a,b; Sapolsky, 1983; Smuts, 1985 ) and seldom exhibit affilitative behaviors toward one another, such as resting in close proximity or grooming (Ransom, 1981; Smuts, 1985). In some troops, including the one that we studied, fights between males occur almost daily; and, because their canines make such effective weapons, injuries are

common. Despite this, a male baboon will greet by presenting his vulnerable hindquarters to another male, and in some cases, even allow his genitals to be touched, literally placing his future reproductive success in the palm of a potential rival's hand. Given their general pugnacity, why do male baboons greet? And why do they tolerate greeting gestures such as genital touching that make them so vulnerable to other males? These questions motivate the present study.

Of the previous work on male greetings cited above, DeVore (1962) briefly considers how greetings reflect patterns of male coalition formation. In contrast, the studies by Sugawara (1979), Anthoney (1968), Pelaez (1982), and Hausfater and Takacs (1987) focus on the relationship between roles adopted when greeting and relative dominance rank. All agree that the lower-ranking male is more likely to present, and the higher-ranking male is more likely to touch or mount the other. These patterns have led several observers to suggest that greetings function to reinforce dominance rela- 
tionships, thereby reducing tension and assuaging aggression (Hausfater and Takacs, 1987; DeVore, 1962; Sugawara, 1979; Pelaez, 1982; Popp, 1978). However, our data show that the relation between greeting roles and relative dominance rank varies significantly across the different age and residence classes of the males involved. This variation suggests the need to consider greetings systematically in relation to other aspects of male-male relationships, especially coalitional or cooperative behavior.

Consequently, in this paper, we describe a detailed study of male-male greetings in a troop of wild olive baboons, with particular attention to how greetings reflect important aspects of male social relationships. In particular, we examine: (a) greetings in relation to relative age and residence status, variables found to be associated with differences in male-male relationships in previous research on this baboon population (Smuts, 1983a,b, 1985; Strum, 1982, 1987; Manzolillo, 1982); and (b) the possible relationship between greeting behavior and male coalitions by contrasting the greetings of two pairs of males that represented the opposite extremes of male-male relationships identified in this troop.

To address the question of why greetings take the form that they do, including the vulnerability of genital touching, we suggest that male baboon greetings can be viewed as rituals of social coordination or cooperation whose efficacy is enhanced through acts that entail vulnerability. In making this argument, we draw on anthropological analyses of human ritual and propose formal similarities between male baboon greetings and certain features of ritual in general.

\section{METHODS}

The results are based on 4 months of intensive observations of the Eburru Cliffs troop of Papio anubis (olive) baboons near Gilgil, Kenya, by both authors from May through August 1983. The study site and troop history are described by Smuts (1985). When the study began, Eburru Cliffs troop had 150 members, including 21 adult and subadult males, the subjects of the greeting study. Here we limit our discussion to greetings observed among the 12 fully adult males in the group.

Greetings were recorded during both focal animal and ad libitum sampling (Altmann, 1974). We conducted nearly 200 focal samples of 30 min duration, distributed evenly across the 12 adult males and over different times of the day, resulting in a total of $93 \mathrm{hr}$ of focal animal data. While one observer was conducting focal samples, the second conducted ad libitum observations, focusing on male-male interactions, including agonism, supplants and avoids, aggression, and greetings. Focal and ad libitum samples resulted in data on 637 greetings among fully adult males. 
Twelve percent of these greetings occurred during focal samples, the remainder during ad lib observations. In the analyses reported here, we lump data from focal and $a d$ lib samples since focal samples sizes were too small to permit statistical analysis. We consider use of ad libitum data appropriate because our analyses do not involve estimates of rates of behaviors but focus, instead, on the form that the greetings took and the roles that each male played. Since all the greetings analyzed here occurred in the same "neutral" context, we believe that ad libitum recording is unlikely to have introduced systematic biases (Hausfater and Takacs, 1987).

For each greeting, we recorded on a checksheet the context in which it occurred, the identity of the approacher, the gestures exchanged, and the manner in which the interaction ended. We also noted whether the greeting was "complete" (the males separated only after the gestural exchange was over), "partial" (the males separated during the gestural exchange, before it was completed), or "incomplete" (the males separated before any exchange of gestures was initiated). Even though incomplete greetings did not involve any gestural exchanges, these interactions could be identified as greeting attempts by the distinctive gait, lip-smacking, and characteristic facial expression accompanying the approach.

Most greetings occurred in a neutral context. We defined the context as neutral when: (a) both the approacher and the approached males were resting, traveling, or foraging immediately preceding the greeting; (b) neither male was involved in an aggressive interaction involving threats, chasing, or fighting during the minute preceding the greeting; and (c) neither male was involved in forming a coalition or contesting a resource, such as an estrous female or prey item, during the minute preceding or following the greeting. This ruled out contexts in which males used greeting gestures to try to solicit support from an ally during an agonistic interaction with a third male, as described by Packer (1977).

Adult males were divided into two classes, depending on their age and length of tenure in the group. Older residents ("old" males) were past their physical prime and had lived in the troop for at least 2 years; three of the four old males had been in the troop for at least 6 years and were estimated to be at least 14 years old. "Young" males were adult males in their physical prime. Some had recently transferred into the group; others were natal males estimated to be between 8-11 years of age, most of which would eventually transfer to other troops (see Smuts, 1985, for further details). Four young males (three natal and one transfer male), which approached fully adult males in size and development of secondary sexual characteristics, were classified as subadults and excluded from this analysis because, unlike other young adult males, they ranked below all old males and failed to form sexual consortships during peak estrus. 
Male dominance ranks (Table I) were based on the outcomes of 175 dyadic agonistic encounters involving unilateral aggressive and submissive gestures. Consort scores (Table I) were based on the identities of consorting males for days D-7 through D-1 of 14 female estrous cycles. A male received one point for each morning or afternoon that he was observed in consort (see Smuts, 1985, for details). Note that although all young males ranked above all old males, on average, old males spent slightly more time in sexual consortships during the day than did young males (see Smuts, 1985, for details).

\section{Data Analysis}

We examined the following characteristics of greetings: (a) types of gestures employed; (b) probability of completing a greeting; (c) relationship between dominance and initiation of the greeting; and (d) relationship between dominance and adoption of the active role in performing greeting gestures. The Kruskal-Wallis one-way analysis of variance was used to test

Table I. Age/Residence Status, Agonistic Ranks, and Consort Success of Adult Males

\begin{tabular}{cccc}
\hline Male & $\begin{array}{c}\text { Agonistic } \\
\text { rank }\end{array}$ & $\begin{array}{c}\text { Consort } \\
\text { score }\end{array}$ & $\begin{array}{c}\text { Median } \\
\text { consort } \\
\text { score by age/ } \\
\text { residence class }\end{array}$ \\
\cline { 1 - 2 } Young adult males & & & \\
DT & 1 & 18 & \\
OV & 2 & 16 & \\
BA & 3 & 2 & \\
OR & 4 & 10 & 8.0 \\
VU & 5 & 4 & \\
JP & 6 & 6 & \\
VL & 7 & 11 & \\
GR & 8 & 5 & \\
Older, long-term & & & \\
resident males & & & \\
ZM & 9 & 13 & \\
BZ & & 4 & \\
AA & 10 & 12.0 \\
SK & 11 & 12 & \\
\hline
\end{tabular}

${ }^{a}$ Part way through the study, BZ suffered a deep gash on the palm of his hand (cause unknown). This injury eventually healed, but it severely interfered with his ability to compete for estrous females during the remainder of the study period. Based on BZ's behavior prior to the injury, it is likely that his normal consort activity was roughly equal to that of the other older resident males. 
the null hypothesis that variation in greeting characteristics was independent of male age/residence classes (old-old pairs, old-young pairs, and young-young pairs). The analyses were based on scores for each male-male dyad, so that each dyad contributed equally to the results. Dyads with less than three greetings were excluded from the analysis. Values shown in the tables represent median scores calculated across individual dyads. Statistical tests were two-tailed unless otherwise indicated.

To determine whether the distance between males in the dominance hierarchy influenced the outcome of greeting attempts, we determined for each dyad (a) the percentage of incomplete greetings (see below) and (b) their dominance rank differential (the difference between the ranks of the two males, which ranged from 1-11). We then grouped together all dyads with the same rank differential value and determined, for each value, the mean percentage of incomplete greetings. Thus, again, each dyad was given equal weight in the analysis.

\section{RESULTS}

\section{Description of Male-Male Greetings}

A greeting typically begins when one male, A, approaches another, B, with a rapid, swinging, gait. During the approach, A looks directly at B and often lip-smacks and makes the narrowed eyes, ears-back face (labeled "NEEF" face by Packer, 1979a, and "come hither" face by Strum, 1987, and Smuts, 1985); both are friendly behaviors. B sometimes avoids A or rejects the approach by turning away his face or body, in which case A ceases approaching. Alternatively, $B$ can accept the approach by maintaining eye contact with A and, often, reciprocally lip-smacking and making the NEEF face. After A approaches B, two or more of the following behaviors can be exchanged, including posterior present, grasping the other male's posterior, mounting, pulling the penis, fondling the scrotum, and, less often, face to body nuzzling or, rarely, embracing. Usually, the roles taken during the greeting ritual are asymmetrical: for example, A presents his hindquarters and B grasps A's hips. Occasionally, the exchange is mutual: for example, A and $B$ touch one another's scrotums. Immediately after the exchange, one male (or, less often, both) moves rapidly away using the same swinging gait characteristic of the approach. The entire sequence is performed quickly and takes no more than a few seconds.

It is important to stress that, at any point after the initial approach, one or both participants may break off the greeting and move away. In some cases, considerable jockeying for position occurs to determine which 
adopts which role. Most, but by no means all, of the greetings are tense and tentative interactions, and in our sample 7\% erupted into aggression (threats, chases, or attacks). Thus, once a greeting began, it did not always result in a full exchange of gestures.

In Eburru Cliffs troop, all juvenline, subadult, and adult male baboons greeted in this manner. During the 4-month study, all but one of the 66 adult-adult dyads were observed greeting at least once; the median number of greetings per dyad being 7.5 . These greetings were unique to males: greeting behaviors observed between females and between female and male baboons took a very different form (Ransom, 1981; Smuts, 1985).

\section{Frequency and Contexts of Greetings}

Focal samples indicated that greetings were by far the most common form of male-male interaction. Males participated in agonistic interactions involving aggressive and submissive gestures, including escalated aggression and polyadic agonistic bouts, at the rate of $0.25 / \mathrm{hr}$ (data for all focal samples were lumped for this analysis). They participated in supplants or avoids, without any exchange of submissive gestures, at the rate of $0.52 / \mathrm{hr}$. Males engaged in greetings at the rate of $1.2 / \mathrm{hr}$. Thus, greetings occurred more than twice as often as the next most common type of male-male interaction.

During focal samples, $98 \%$ of all greetings occurred in neutral contexts; and, during ad libitum samples, $97 \%$ occurred in neutral contexts. Thus, the overwhelming majority of greetings took place during routine foraging, resting, or traveling when the males were not involved in any other social interactions. In the analysis that follows, we excluded the 18 greetings that occurred in nonneutral contexts.

\section{Probability of Completing Gestural Exchanges}

Nearly one quarter $(24 \%)$ of all greetings ended before any gestural exchanges were initiated (incomplete greetings); another $21 \%$ were interrupted before the gestural exchange was complete (partial greetings) (Table II). Across all dyads, the median percentage of completed greeting attempts was $50 \%$. However, the likelihood of completing a greeting varied singificantly by age/residence class combinations (Table II). Two thirds of the old-old male greetings were completed, compared with only one third of the young-young greetings: old-young dyads had an intermediate percentage $(56 \%)$ of completed greetings. Similarly, young-young pairs were more likely to end a greeting attempt before any gestural exchange was initiated 
Table II. Percentage of Incomplete, Partial, and Complete Greetings ${ }^{a, b}$

\begin{tabular}{lccccc}
\hline $\begin{array}{c}\text { Age/residence } \\
\text { class }\end{array}$ & $\begin{array}{c}\text { Number } \\
\text { combinations }\end{array}$ & $\begin{array}{c}\text { Number } \\
\text { of } \\
\text { greeting } \\
\text { attempts }\end{array}$ & $\begin{array}{c}\text { Median } \\
\text { percentage of } \\
\text { incomplete } \\
\text { greetings }\end{array}$ & $\begin{array}{c}\text { Median } \\
\text { percentage } \\
\text { of partial } \\
\text { greetings }\end{array}$ & $\begin{array}{c}\text { Median } \\
\text { percentage } \\
\text { of complete } \\
\text { greetings }\end{array}$ \\
\hline All & 53 & 600 & 23.08 & 21.43 & 50.00 \\
Old-old & 5 & 73 & 16.67 & 15.38 & 66.67 \\
Old-young & 27 & 297 & 20.00 & 25.00 & 55.56 \\
Young-young & 21 & 230 & 39.29 & 21.00 & 33.33 \\
\hline
\end{tabular}

${ }^{a}$ See text for definitions.

${ }^{b}$ Kruskal-Wallis one-way analysis of variance by age/residence class combinations - incomplete greetings: $H=6.62, p=0.036$; partial greetings: $H=0.88, p=0.644$; complete greetings: $H=10.43, p=0.005$.

'Twelve dyads with $<3$ greeting attempts were excluded.

$(39 \%)$ than were old-old pairs $(17 \%)$ or old-young pairs $(20 \%)$. The percentage of partial greetings, however, did not vary significantly by age/ residence class combinations (Table II).

These results indicate that males had difficulty completing many of their greeting attempts. In some cases, the source of difficulty was obvious: one male actively resisted the greeting by pulling his body away from the other's attempt to grasp his posterior, mount him, or touch his genitals. Young-young dyads showed a higher percentage of such resists $(\mathbf{2 8 \%})$ than did old-old $(15 \%)$ or old-young $(17 \%)$ dyads; however, these differences were not significant (Kruskal-Wallis one-way analysis of variance, $H=$ $0.92, p=0.630$ ).

Subjectively, it appeared that males had difficulty completing greetings when their relationships were particularly tense or ambivalent. Furthermore, it seemed that particularly tense/ambivalent relationships characterized males that were very close in dominance rank. To test this hypothesis, we correlated the mean percentage of incomplete greetings with dominance rank differential for young-young, young-old, and old-old pairs separately. The correlation was significant for young-young pairs $\left(r_{s}=\right.$ $0.79, n=7, p<0.05$ ) but not for the other age/residence combinations.

\section{Frequency of Different Types of Gestures}

Partial and complete greetings involved primarily three types of gestures or gestural attempts: (a) one male grasped or tried to grasp the other's posterior with one or both hands (median $=41 \%$ ); (b) one male mounted or attempted to mount the other $(48 \%)$; or (c) one or both males touched or tried to touch the other's genitals $(18 \%)$ ) (hereafter referred to as "diddling" following Ransom, 1981) (Table III). In addition, 7\% involved 
Table III. Occurrence of Three Types of Gestures During Partial and Complete Greetings ${ }^{a-c}$

\begin{tabular}{lccccc}
\hline $\begin{array}{c}\text { Age/residence } \\
\text { class } \\
\text { combinations }\end{array}$ & $\begin{array}{c}\text { Number } \\
\text { of dyads }\end{array}$ & $\begin{array}{c}\text { Number of } \\
\text { greetings }\end{array}$ & $\begin{array}{c}\text { Median } \\
\text { percentage } \\
\text { involving } \\
\text { grasp } \\
\text { posterior }\end{array}$ & $\begin{array}{c}\text { Median } \\
\text { percentage } \\
\text { involving } \\
\text { mounts }\end{array}$ & $\begin{array}{c}\text { Median } \\
\text { percentage } \\
\text { involving } \\
\text { genital } \\
\text { touching }\end{array}$ \\
\hline All & 42 & 398 & 41.26 & 48.00 & 18.34 \\
Old-old & 3 & 54 & 66.67 & 55.56 & 0 \\
Old-young & 24 & 216 & 33.33 & 50.00 & 14.29 \\
Young-young & 15 & 128 & 64.29 & 18.75 & 25.00 \\
\hline
\end{tabular}

${ }^{a}$ Incomplete greetings that included no gestural exchanges were excluded (see Table II).

${ }^{b}$ Percentages across the three types of gestures may sum to more than 100 because some greetings involved more than one type of gesture.

${ }^{c}$ Kruskal-Wallis one-way analysis of variance by age/residence class combinations - grasp posterior: $H=8.54, p=0.014$; mounts: $H=11.91, p=0.003$; genital touching: $H=3.98, p$ $=0.137$.

${ }^{d}$ Twenty dyads with $<3$ partial or complete greetings were excluded.

one male nuzzling the other's back with his nose (usually during a mount); and $6 \%$ involved some other form of touching.

In partial and complete greetings, the frequencies of the two most common greeting gestures, grasp posterior and mount, varied significantly by age/residence class combinations (Table III). Old-old dyads and young-young dyads frequently employed the grasp posterior gesture (67\% and $64 \%$ of partial and completed greetings, respectively); however, old-young dyads grasped posterior less often $(33 \%)$. On the other hand, old-old and old-young dyads often mounted ( $56 \%$ and $50 \%$, respectively), but young-young dyads rarely did so (19\%). Diddling was relatively uncommon for all age/residence class combinations and did not differ significantly across them (Table III).

\section{Dominance and Roles Adopted During Greetings}

We tested the hypothesis that the more dominant male of a greeting dyad tends to take a more active or assertive role in the greeting by examining (a) whether the higher-ranking male was more likely to perform the approach that initiated the greeting, and (b) whether the higher-ranking male tended to perform the gesture (grasp posterior, mount, or touch genitals) while the lower-ranking male tended to receive it.

Within each of the three age/residence class combinations, there was a significant tendency for the dominant animal to approach more often than the subordinate (Sign test, one-tailed: old-old dyads, $n=5, x=0, p=$ 0.031; old-young dyads, $n=26, x=1, p=0.000$; young-young dyads, $n$ $=20, x=5, p=0.021$ ). However, the median percentage of approaches 
Table IV. Relative Dominance Rank and Initiator Role During Greetings ${ }^{a}$

\begin{tabular}{lccc}
\hline $\begin{array}{c}\text { Age/residence } \\
\text { class }\end{array}$ & $\begin{array}{c}\text { Number of } \\
\text { dyads }^{b}\end{array}$ & $\begin{array}{c}\text { Number of } \\
\text { greetings }^{c}\end{array}$ & $\begin{array}{c}\text { Median percentage } \\
\text { of greetings initiated } \\
\text { by dominant male }\end{array}$ \\
\hline All & 53 & 577 & 85.71 \\
Old-old & 5 & 70 & 100.00 \\
Old-young & 27 & 284 & 90.91 \\
Young-young & 21 & 223 & 71.43 \\
\hline
\end{tabular}

${ }^{a}$ Kruskal-Wallis one-way analysis of variance by age/residence class combinations: $H=6.11, p=0.047$.

${ }^{b}$ Twelve dyads with $<3$ greeting attempts were excluded.

'Twenty-three greetings were excluded because the initiator was not observed $(n=17)$ or because both males approached simultaneously $(n=6)$.

made by the dominant animal varied significantly by age/residence class combinations (Table IV). Young-young dyads showed a lower percentage of approaches by the dominant animal $(71 \%)$ than either old-young $(91 \%)$ or old-old dyads $(100 \%)$.

Within old-young pairs, the dominant animal performed the gesture significantly more often than the subordinate did (Sign test, one-tailed, $n=$ $24, x=1, p=0.001$ ). This tendency held for two of the three old-old pairs that exchanged gestures often enough to be included in the analysis, but the sample size was too small for statistical analysis. However, youngyoung pairs showed no tendency for dominants to perform the gesture more often than subordinates; in fact, they showed a nonsignificant trend in the opposite direction (Sign test, one-tailed, $n=12, x=5, p=0.387$ ). The median percentage of gestures performed by the dominant animal varied significantly by age/residence class combination (Table V). In both old-old pairs and old-young pairs, a large proportion of gestures was performed by the dominant animal $(75 \%$ and $93 \%$, respectively); however, among young-young dyads, the median percentages of gestures given by dominants and by subordinates were exactly the same $(50 \%)$.

\section{Greetings and Dyadic Relationships}

The results presented above indicate that several characteristics of male-male greetings vary as a function of the age/residence classes of the greeting males. Below, we discuss this variation in more detail. First, however, we examine further how greeting patterns differ between dyads by looking more closely at two dyads that had very different relationships: the two highest-ranking young males, $O V$ and DT, and the two old males with the oldest and strongest coalitionary relationship, AA and BZ.

OV and DT grew up in the Eburru Cliffs troop together and were roughly the same age (around 9 years). Their dominance relationship was 
Table V. Relative Dominance Rank and Adoption of Active Role During Greetings $^{a}$

\begin{tabular}{lccc}
\hline $\begin{array}{c}\text { Age/residence } \\
\text { class } \\
\text { combinations }\end{array}$ & $\begin{array}{c}\text { Number of } \\
\text { dyads }^{b}\end{array}$ & $\begin{array}{c}\text { Number of } \\
\text { gestures }^{c}\end{array}$ & $\begin{array}{c}\text { Median percentage of } \\
\text { gestures where } \\
\text { dominant male } \\
\text { adopted the active role }\end{array}$ \\
\hline All & 42 & 461 & 80.00 \\
Old-old & 3 & 74 & 74.53 \\
Old-young & 24 & 235 & 92.52 \\
Young-young & 15 & 152 & 50.00 \\
\hline
\end{tabular}

${ }^{a}$ Kruskal-Wallis one-way analysis of variance by age/residence class combinations: $H=13.15, p=0.001$.

${ }^{b}$ Twenty dyads with $<3$ partial and or complete greetings were excluded. ${ }^{c}$ Includes grasp posterior, mount, and touch genitals.

unclear: we never saw a dyadic agonistic interaction between them (we ranked DT Above OV in Table I because DT dominated a larger number of other males than OV did). The difficulty young males had completing greetings is especially well illustrated by this pair. During the study we saw OV initiate a greeting with DT seven times, but the interaction was always aborted before any gestural exchanges occurred. One typical attempt went as follows:

DT is resting. OV approaches from behind, lip-smacking. DT quickly stands and swerves around to face $\mathrm{OV}$, lip-smacking. OV pauses a few meters away and then moves toward DT at an angle, as if again to approach from behind. DT turns his posterior away from $\mathrm{OV}$ and moves rapidly behind him. OV swivels his hips away from DT, and then both males, still lip-smacking, simultaneously reach toward the other's posterior. Both males again swerve their posteriors away; this time, they keep moving, ending the greeting attempt.

The relationship between $\mathrm{AA}$ and $\mathrm{BZ}$ exemplifies the other extreme. They took turns helping one another take estrous females away from other males, and they also protected one another against aggression by young, high-ranking rivals (Smuts, 1985). Their greetings had several unique features. First, they greeted more often than most other dyads (they tied for rank 4 out of 66 dyads in greeting frequency during focal samples and surpassed all other dyads in greeting frequency during ad libitum observations). Second, $93 \%$ of their greetings were completed, compared with a median of $50 \%$ for all dyads (out of 53 dyads that greeted at least three times, only two others completed $>90 \%$ of their greetings; both involved AA and young adult natal males). Third, AA and BZ showed a unique combination of characteristics with regard to diddling, the seemingly most risky and intimate form of greeting: their greetings involved frequent use of this gesture $(42.5 \%$ of their greetings), no attempts to resist the gesture, and similar frequencies of adopting active and passive diddling roles (see Fig. 1). Fourth, and most strikingly, they were the only dyad that showed complete symmetry in greeting roles for all three types of gesture (Fig. 1). 


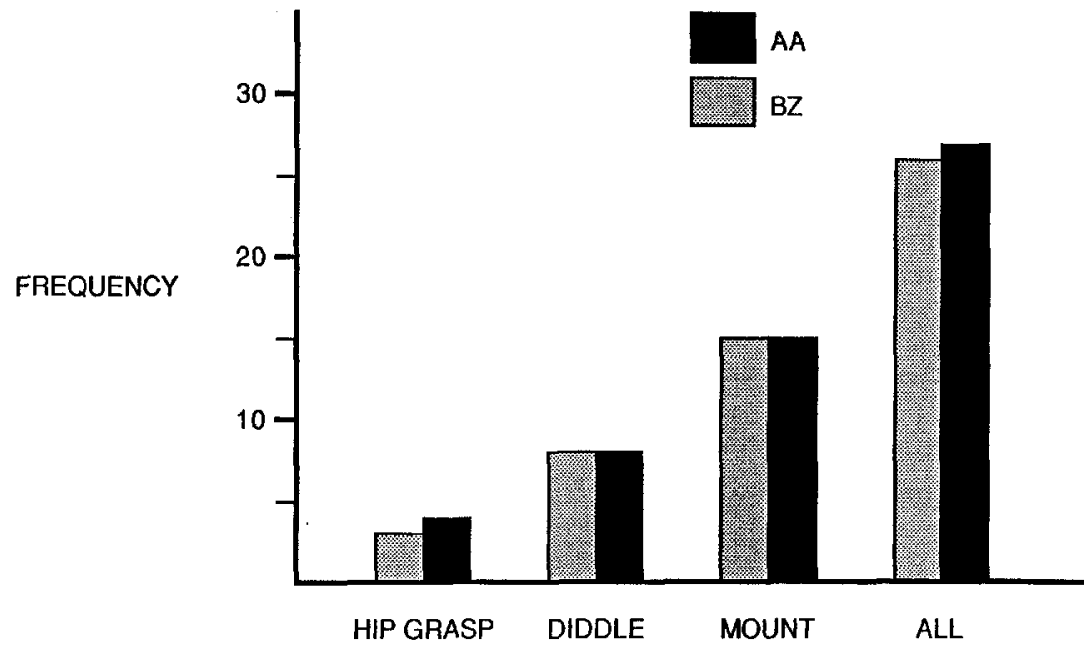

Fig. 1. Frequency with which $A A$ and $B Z$ adopted the active or passive role for different types of greetings (based on 43 gestural exchanges in 41 completed greetings). The probability $(P)$ of achieving exactly the distribution of active and passive roles observed for each type of greeting was calculated using the binomial expansion, where the probability of each male adopting the active or passive role was equal. $P_{d}$ (greetings involving diddling) $=0.27$, $P_{p}$ (greetings involving posterior grasp) $=0.20$, and $P_{m}$ (greetings involving mounts) $=0.14$. $P$ for all greetings $=P_{d} \times P_{p} \times P_{m}=0.0076$.

As Fig. 1 indicates, the probability that greeting roles between AA and $\mathrm{BZ}$ would conform as closely to equality as they actually did, across all three types of greetings, is extremely small. This suggests that AA and BZ sought to create symmetry in their greetings by balancing the active vs. passive roles across greetings. This hypothesis is supported by 10 observations of two or more greetings in quick succession by $\mathrm{AA}$ and $\mathrm{BZ}$ in a neutral context. Usually, these successive greetings occurred early in the morning, when the pair greeted for the first time that day. Their greetings on the morning of July 19, 1983 are a good example:

7:48 AM: BZ approaches AA and presents; AA grasps BZ's posterior with both hands.

7:50 AM: AA approaches $\mathrm{BZ}$ and presents; $\mathrm{BZ}$ grasps AA's posterior with both hands.

The 10 occasions in which AA and BZ greeted in quick succession involved five instances of three greetings in a row and five of two, resulting in a total of 15 successive sets of greetings. Three of the 15 involved mutual, simultaneous gestures and were eliminated from the analysis. Of the remaining 12, 9 conformed to the scenario depicted above: the male who had adopted the passive role in the previous greeting adopted the active role in 
the subsequent greeting. In theory, this pattern could occur in one of two ways: (1) by "demand" in which male A adopts the active role in the first greeting, and then male $B$ initiates a subsequent greeting in which he adopts the active role; or (2) by "courtesy," where male A adopts the active role in the first greeting, and then male A initiates the subsequent greeting and presents his posterior, thereby inviting $B$ to adopt the active role (as in the example given above). Eight of the nine cases conformed to the courteous scenario; in the ninth, male $\mathrm{A}$ initiated the subsequent greeting but did not present his posterior.

To determine whether the pattern shown by $\mathrm{AA}$ and $\mathrm{BZ}$ was unique, we examined greetings performed in quick succession by other dyads. Twenty-one such instances were observed involving 14 dyads (6 old-young and 8 young-young dyads; greetings in which either male was in consort were excluded). Only 8 of the 21 pairs of successive greetings showed alternation of active and passive roles (these involved 4 of the 14 dyads; all were young-young pairs), and only one of these role alternations conformed fully to the "courteous" scenario. Five cases involved "partial courtesy," where the previously active male approached but did not pressent $(n=2)$ or presented but did not approach $(n=3)$. The remaining two cases conformed to the "demand" scenario described above. Thus, AA and BZ appeared to be the only dyad in the troop that (a) frequently alternated passive and active gestural roles and (b) consistently accomplished role alternations via "courtesy."

\section{DISCUSSION}

\section{Frequency and Context of Greetings}

Greetings occurred more than twice as often as any other type of male-male interaction, suggesting that they serve an important function. The neutral context in which the vast majority of greetings occur provides clues about what this function might be. Males seek out greetings at times when there is no resource at stake, and they seem to avoid greeting rivals during, or immediately afer, competitive interactions over resources. The absence of a contested resource means that the greeting approach is unlikely to be misinterpreted as an agonistic act. Potential ambiguity about the approacher's motives is further reduced by the lip-smacking, friendly facial expression, and distinctive, swinging gait that accompany the approach. The swinging gait also marks the end of the greeting. These features "frame" the greeting, so that it is set off clearly from all other kinds of male-male interactions. We believe that this framing behavior, combined with the neutral 
context, perhaps serves to establish a kind of temporary "truce" or "neutral ground" on which relations between the greeters can be explored, or even constituted, with minimal risk of injury. Although $7 \%$ of greetings did erupt into agonism, none of the 637 greetings among adult males resulted in a wound. Injuries occurred more often when males competed over a resource, presumably because the potential payoff of escalated aggression was greater for both males. If males can sometimes "work out" aspects of their relationships in advance of contests over resources, then both males may benefit through reduced rates of escalated aggression and injury. We suggest that greetings sometimes serve this function. However, in order to clarify exactly what males attempt to "work out" in their greetings, we first review patterns of male-male relationships and then consider how greetings varied as a function of these social relationships.

\section{Age/Residence Status, Competitive Tactics, and Male-Male Relationships}

Smuts (1985) showed that old and young adult males in the Eburru Cliffs troop used very different tactics to gain access to estrous females. older residents acquired them from young males, mainly during the day, by forming coalitions with other older residents. During the study period, we observed 13 coalitions involving 2-4 older males that led to consort turnovers. In all 13 instances: (a) the coalition challenged a young adult male; and (b) an older resident acquired the female. Only once did we observe an older resident take an estrous female from another male without the help of another, older resident.

In contrast, young adult males acquired females primarily on their own at dawn, dusk, or overnight on the sleeping cliffs. We observed six successful consort challenges by young adults. None involved coalitions, and all were directed toward older residents. We saw young adult males join coalitions of older residents three times; however, they were never seen to acquire females in this manner.

These differences in competitive tactics were accompanied by differences in male-male relationships. OIder residents' relationships with one another were cooperative, egalitarian, and generally relaxed. For example, among old males, both participation in coalitions and benefits received from coalition formation were roughly equally distributed: of the four older residents, SK participated in coalitions nine times, AA and ZM participated eight times, and BZ participated six times; SK and AA gained the female four times, $\mathrm{ZM}$ gained the female three times, and $\mathrm{BZ}$ gained the female twice (BZ's reduced participation and access to females was probably a result of a serious wound received partway through the study period). We never observed an older resident challenge the sexual consortship of another 
older resident, and older residents in consort tolerated other older residents in close proximity to their females.

In contrast, young adult male relationships appeared to be extremely tense. We never observed a successful coalition among young males; they appeared to avoid direct competition with one another whenever possible, perhaps due to the high risk of injury (the canines of young males are razorsharp and capable of inflicting serious wounds; the canines of older males are duller and, in many cases, broken at the tip). This avoidance of competition was manifested in three ways (Smuts, 1985). First, young males rarely challenged one another's consortships. Second, they avoided consorting with the same female during the same estrous cycle. Third, they almost never formed long-term affiliative relationships, or "friendships," with the same females (Smuts, 1985, p. 140).

It is more difficult to characterize relationships between older residents and young males. On the one hand, older residents and young males were intense rivals, since each focused their consort challenges on members of the other class. In addition, young males sometimes harassed older residents, at times by persistently supplanting them and at others by circling, yawning, and grinding their canines. Older residents generally responded to the former by calmly moving away, and to the latter by ignoring the threats (Smuts, 1985). On the other hand, some older residents and young males appeared to have relaxed relationships characterized by occasional play and an absence of agonism. Finally, although young males were unequivocally dominant to older residents in dyadic encounters, older residents were often more successful than young males in consorting with females and in gaining access to meat, a characteristic feature of this baboon population (Harding, 1980; Smuts, 1982; Strum, 1982, 1987; Manzolillo, 1982; Scott, 1984; Berkovitch, 1986).

\section{Greeting Patterns and Male Social Relationships}

The results described above suggest three patterns of greetings among adult male baboons of Eburru Cliffs that reflect, in turn, the three different types of social relationships found among the three combinations of age/residence classes.

In the first pattern, typical of greetings between young, high-ranking adult males, nearly $40 \%$ of greeting attempts ended before gestural exchanges began; and when young males attempted gestural exchanges, a relatively high proportion of them $(28 \%)$ were actively resisted. Incomplete greetings were significantly more common when the males were close in rank. Dominant males were somewhat more likely to initiate the greeting than subordinates; however, dominance status had no detectable influence 
on which male adopted the active role during gestural exchanges. Many $(64 \%)$ young-young greetings involved the grasp posterior gesture. In contrast to old-old and old-young greetings, mounts were uncommon (19\%).

Taken together, these tendencies indicate that greetings between young males were especially tense and ambivalent. Qualitative observations, such as those described for OV and DT above, suggest that young males had difficulty completing their greetings, at least in part because they were often unable to agree about which male would adopt the more vulnerable, passive role. Ambiguity about greeting roles among young males is consistent with the relative instability of their dominance relationships. Within 6 months of the completion of this study, several dramatic changes in rank occurred among the young adults (Noë, personal communication). Furthermore, the particularly tense nature of their greetings, revealed by the high proportion of incomplete greets and gestural resists, is consistent with the tendency of younger males to minimize interaction by avoiding direct competition for consorts and by forming neither sexual nor social relationships with the same females.

On the other hand, despite their tense relationships, young-young pairs frequently attempted to greet; and greetings often represented the primary form that their social interactions took. Again, the two top-ranking males provide a good example. DT and OV never attempted to supplant one another, and neither directed threatening or submissive gestures toward the other. Yet they tried to greet seven times. Thus, young males may sometimes use greetings to explore dominance relationships before testing those relationships in other, potentially more dangerous, contexts. Similar$\mathrm{ly}$, in laboratory experiments, male hamadryas baboons tried greeting as a first interaction and settled dominance by fighting only if the greeting attempt was avoided (Sigg, 1981).

A second pattern characterized greetings between young males and older residents. Eighty percent of these greetings proceeded to the gesturalexchange stage, and $56 \%$ were completed. A proportion (17\%) of gestural attempts was nevertheless resisted; two thirds of these resists involved young males refusing an older male's attempt to adopt the more active role. In nearly all of their greetings, the more dominant, young male initiated the greeting $(91 \%)$ and adopted the active role $(93 \%)$. In contrast to old-old and young-young greetings, old-young greetings more often involved mounts $(50 \%)$ than the grasp posterior gesture $(33 \%)$.

Among old-young dyads, dominance relationships were very clear-cut and stable: young males always ranked above older males. The relatively high proportion of completed greetings and the congruence between rank and roles appear consistent with the clear-cut and uncontested status relationships between these two classes of males. As several other researchers have suggested, perhaps these greetings serve to reinforce status relation- 
ships. However, if status relationships between young and old males are so clear-cut, why should it be necessary to reinforce them through greetings?

We have no answer to this question, and would like to suggest an alternative hypothesis. Perhaps young and old males use greetings to explore the possibility of developing cooperative interactions. Young adult males are clearly superior to older residents in terms of fighting ability; however, paradoxically, older residents often surpass young males where it matters most: access to meat and access to estrous females. The older residents' success in acquiring resources seems to be related to their close network of reciprocal alliances (Smuts, 1985) and their affiliative relationsips with females and infants (Smuts, 1985; Strum, 1983, 1984). The possession of very different advantages by young and old males may provide opportunities for cooperation. Reduced agonism and increased tolerance between an old and a young male might facilitate the young male's access to social resources. For instance, a more tolerant relationship with an older male might increase a young male's chances of forming a friendship with a female that is already friends with the older resident. In the Eburru Cliffs group, most young adult males, in fact, shared their female friends with an older resident (Smuts, 1985). Relationships with young males may benefit old males in several, subtle ways. For example, we observed great variation in the frequency with which individual young males supplanted individual old males during feeding; a lower supplant rate is one possible benefit a young male could confer on an older one. On two occasions, we had the distinct impression that a young, consorting male, being harassed by a coalition of old males, timed his abandonment of his consort partner in such a way that a particular old male gained the female. Such intentions are extremely difficult to demonstrate; however, we should not rule out the possibility of such helpful acts simply because we have not yet determined how to document them. While this hypothesized relationship of greetings to cooperation between older residents and younger males remains very speculative, it is testable. For example, one could examine greetings between old and young dyads from the moment that young males enter a troop (or approach adult status, if in their natal troop) and compare changes in their greetings with changes in other aspects of their relationship, such as supplant rate or association with the same female.

Old-old pairs represented a third greeting pattern. They had the highest percentage of completed greetings $(67 \%)$ and the lowest frequency of greetings interrupted before gestural exchanges were initiated $(17 \%)$. They resisted one another's gestural attempts less often $(15 \%)$ than the other age/residence class combinations. The relationship between dominance and greeting roles varied across old-old dyads, because AA and BZ showed a different pattern from the others. When the AA-BZ dyad is excluded, we find a strong tendency for the dominant animal to initiate the 
greeting $(93 \%)$ and to adopt the more active gestural role $(100 \%)$. Both the posterior grasp gesture $(67 \%)$ and mounts $(56 \%)$ were commonly used in old-old greetings.

In general, dominance relationships between old males appeared to be clear-cut but relatively unimportant. They seemed uninterested in contesting rank, perhaps because they obtained estrous females primarily through cooperation with one another and never by competing against one another (Smuts, 1985). The high percentage of completed greetings and low frequency of resistance to gestural exchanges are consistent with other aspects of their relationships, including little tension and considerable cooperation.

Greetings between $\mathrm{AA}$ and $\mathrm{BZ}$ represented a fourth pattern, unique to this dyad in the Eburru Cliffs group. AA and BZ showed complete symmetry in their greeting roles. Furthermore, this symmetry was achieved via "courtesy" instead of "demand," suggesting that achievement of symmetrical greeting roles was more important to both males than were opportunities to adopt the active role at the partner's expense. AA and BZ had the most stable coalitionary relationship among males in the group (their coalition formed in 1978, 5 years before this study began); they shared the rewards of their coalition, and they were the only males that defended one another against higher-ranking rivals. The reciprocity that they took such pains to achieve in their greeting relationship mirrored the reciprocity seen in their coalitionary relationship.

\section{Greetings and Cooperation}

The relationship between $\mathrm{AA}$ and $\mathrm{BZ}$ illustrates two aspects of cooperation, which can, in theory, be independent. One aspect involves inhibition of competition against another animal; the other involves active cooperation between two animals against a third. Data from several other studies support the suggestion that male-male greetings may be related to both aspects.

In his field study of hamadryas baboons, Kummer (1968) hypothesized that males that respected one another's females and that allied with one another during large scale fights, involving several one-male units, were the ones that frequently presented to one another. Abegglen (1984) confirmed that among wild hamadryas, "notifying" (a highly ritualized form of greeting characteristic of hamadryas baboons) occurs most often between members of the same band, which includes related males that cooperate in protecting their females from rival males (Kummer, 1984). Within the band, male "leaders" (the breeding males of one-male units) notify their "followers" (subadult or young adult males that associate with the 
leader's unit) significantly more often than expected (Abegglen, 1984). Kummer (1975) concluded, from his experiments with gelada and hamadryas baboons, that presenting and notifying reduced agonistic motivation in the recipient. Similarly, Abegglen presents evidence that, in the wild, leaders notify followers in order to reduce the chances that aggressive rivalry over females will disrupt their cooperative bond. Abegglen (1984) also provides evidence indicating that, during foraging, hamadryas males from the same clan use notifying as a way to coordinate the daily travel route, a form of male-male cooperation apparently unique to this species (see also Sigg and Stolba, 1981). Finally, Kummer (1975) found that when unfamiliar, captive gelada and hamadryas baboon male-female and female-female dyads initiate their relationships, the subordinate performs the first presentation, while the dominant subject does the first mount. However, most male-male dyads reverse the roles. Kummer suggests that "the reversal permits the forming of cooperative bonds even in the highly aggressive male-male dyads, where the subordinate often avoids being mounted, with expressions of extreme fear" (H. Kummer, personal communication).

Further data on olive baboons support a relationship between greetings and cooperative relationships. Ransom (1981) described the behavior of two adult males, David and Grinner, which had transferred into his study troop a short time before. David had the highest number of presents to other males, and solicited support from other males during polyadic agonistic bouts more often than any other male. Grinner had the lowest number of presents, and almost never solicited support from other males. DeVore (1962) presented detailed information on male-male coalitions and greetings for a troop of olive baboons in Nairobi National Park. We compared De Vore's data on male greeting behavior and coalition formation and found that males whose greetings were characterized by symmetry of the active/passive roles (like AA and BZ) were coalition partners significantly more often than expected and were opponents significantly less often than expected, whereas males whose greeting roles were asymmetrical showed the opposite pattern (Table VI).

Observations of male behavior during cooperative aggression against other males also support a link between greetings and coalition formation. When two or more baboon males form an aggressive coalition, they often use brief, telegraphic versions of the same gestures used in greetings to synchronize joint threats against a common rival (Ransom, 1981; Packer, 1977; Smuts, 1985). For example, one coalition partner will run to the other and present his posterior; the other will touch, diddle, or mount him, and immediately afterwards both males will turn and together confront their rival. We hypothesize that when coalition partners employ greeting gestures in this context, they may be referring back to "agreements" already achieved during a series of routine greetings occurring in more neutral contexts. 
Table VI. Greeting Patterns and Male Coalitional Behavior in Olive Baboons in Nairobi Park $^{\alpha}$

\begin{tabular}{|c|c|c|c|c|c|}
\hline \multirow{2}{*}{$\begin{array}{l}\text { Type of greeting } \\
\text { relationship }\end{array}$} & \multirow{2}{*}{$\begin{array}{l}\text { No. of } \\
\text { dyads }\end{array}$} & \multicolumn{2}{|c|}{$\begin{array}{c}\text { No. of times males } \\
\text { were partners }\end{array}$} & \multicolumn{2}{|c|}{$\begin{array}{l}\text { No. of times males } \\
\text { were opponents }\end{array}$} \\
\hline & & Observed & Expected & Observed & Expected \\
\hline Symı & 3 & 27 & 14 & 12 & 24.6 \\
\hline Asymmetric & 10 & 17 & 29.6 & 63 & 50.4 \\
\hline
\end{tabular}

${ }^{a}$ Data are derived from DeVore (1962). Classifications of dyads as "symmetric" or "asymmetric" are based on Anthoney's (1975) discussion of DeVore's results. In "symmetric" dyads, each member shows both the mount and grasp posterior role. In "asymmetric" dyads, mount and/or posterior grasp roles are shown by one member only. Two dyads rarely or never greeted and were eliminated from the analysis. The table shows the number of times that males that had each type of greeting relationship were observed as partners or opponents during polyadic agonistic bouts. Expected values were based on the null hypothesis that the frequencies with which males were partners or opponents were unrelated to their greeting behavior. Coalitional events were of two types: (1) A and B jointly threaten C $(n=19)$ and (2) A solicits B's support against $\mathrm{C}(n=25)$. The distributions of partners and opponents across the two greeting relationships differ significantly from expected distributions $\left(\chi^{2}=25.9\right.$, $n=119$, df $=1, p<0.002$ ).

These findings suggest that it might be profitable to examine greetings in other animals for evidence of a link between greetings and cooperation. For example, chimpanzees engage in formal, stereotyped greetings in which the subordinate animal bobs and pant-grunts to the dominant; and the dominant exhibits behaviors, such as placing one arm over the other, that combine both assertive and friendly components (Goodall, 1986; de Waal, 1982, 1986), just as baboon greetings do. Unlike greetings among male baboons, greeting roles among male chimpanzees always reflect relative dominance status (Bygott, 1974; de Waal, 1986). However, incomplete or attempted greetings are common, so there may be an element of negotiation in chimpanzee greetings as well (de Waal, personal communication). In the absence of regular greetings, tensions in male-male relationships escalate, and nongreeting males are never coalition partners (de Waal, 1982, 1986).

Our results, combined with those from other studies, indicate that male baboon greetings may relate to cooperation of several kinds, in several contexts. However, the nature of this relationship remains unclear. We sugget two possible arguments linking greetings to male-male cooperation, a "weak" and a "strong" form. The weak argument simply asserts that the form that greetings take is congruent with important aspects of the males' social relationships, including their propensity to cooperate. In our view, the data presented here support this hypothesis. The strong form of the argument asserts that males actually use greetings to negotiate and constitute aspects of their relationships, including cooperation. Our results and 
those of other studies provide only circumstantial evidence in support of this hypothesis. To evaluate it, longitudinal studies are needed to determine whether changes in greetings precede changes in the males' relationships that are expressed in other contexts. Our study was too brief to provide such data.

\section{Greetings as Rituals}

The possible relationship between greetings and cooperation links the form and content of the greetings to problems intrinsic to cooperation itself - that is, to evolutionary questions of reciprocal altruism. This brings us briefly, and much more speculatively, to the second question raised at the beginning of this paper: Why do greetings take the form that they do, and why in particular do they involve gestural exchanges such as diddling, which apparently entail physical vulnerability to another male?

A fundamental difficulty in the evolution of reciprocal altruism involves how to initiate the cycle of mutually exchanged benefits in the first place. In a world of self-interested individuals, any overture to reciprocity remains fraught with risk since, by definition, such action presumes the inability of the initiator to coerce an automatic return from a prospective partner. Indeed, all truly cooperative relationships ultimately depend on the mutual agreement of each partner to participate instead of absolute control of one party over the other. Consequently, reciprocal altruists can never guarantee their partners' nondefection but, at best, can ensure themselves of the negative sanction of their own defection. Given this ever-present possibility of defection, vulnerability continually tempers trust; even individuals willing to cooperate confront the problem of how to convince others of their own "good intentions." Before cooperative relationships can be enjoyed, much less manipulated, they must first be established. However, how can the long-term benefits of mutual cooperation come to outweigh the immediate temptations of short-term opportunism?

Trivers (1971) and Axelrod (1984) suggest that relatively bounded social groups of known individuals increase the potential for cooperation by fostering the possibility of repeated, open-ended social interactions, since a reputation for too-frequent defection eventually leaves the inveterate cheater without exploitable partners, at least within the group. Under such circumstances, in order to win the game of reciprocal altruism-or, more accurately, to stay in the game and come out ahead of where one would otherwise-individuals must, however minimally, "play by the rules." This still leaves unresolved the actual way that cooperation gets established.

We have suggested that baboon greetings perhaps serve something of this function by formally establishing a neutral social context, clearly framed 
by the distinctive gait and facial expressions that mark the greeters' approaches and leaves, and within which only a specific repertoire of behaviors can occur. Rappaport (1979a) defines two basic properties of ritual: formality - that is, relatively invariant sequences of acts that the performers themselves do not create but instead follow; and performance - the need for participants literally to engage in the behavioral constraints that set the ritual apart from other "ordinary" activities. He argues that the mutual conformity enacted through ritual constitutes a paradigm for social cooperation because it so simply, yet immediately and unambiguously, subordinates individuals to common behavioral constraints that transcend the individual actors themselves. Consequently, he defines ritual as "the basic social act" (1979a, p. 174): in the absence of some overarching authority, or of the absolute dominance of one party by another, the mutual conformity precipitated by joint observance of a given set of behaviors establishes a common ground of social coordination and cooperation between the ritual's participants. Furthermore, Rappaport argues that the relative invariance of the ritual performance itself also conveys to its participants a perception of unchangeableness - and, therefore, of certainty or truth - which in turn can enhance (without, of course, ever guaranteeing) the sanctity or truthfulness of other social messages that come to be associated with the ritual. In other words, ritual does more than simply reflect certain social states of affairs - its very performance actually brings into being particular states of affairs and at the same time legitimizes them.

Although baboons clearly lack ideas of truth and sanctity in the semiotic sense that Rappaport discusses (1979b), the male greetings described here may well represent just such, albeit elementary, rituals of social cooperation, or at least of social coordination. Several investigators have remarked on the stereotypy and ritualized nature of male baboon greetings (Anthoney, 1975; Pelaez, 1982). Like other ritualized interactions among nonhuman animals (Huxley, 1966; Estes, 1969; Smith, 1977) and humans (Goffman, 1971; Scheflen, 1967), the greetings that we observed conformed to a limited number of configurations, all performed within the same basic format. Indeed, before baboon males could greet at all, each had to "accept" the constraints of the greeting's outward form so that both could then recognize the other's actions as a greeting. At the same time, the roles of the greeters - of who did what to whom, as well as when they chose to greet - remained relatively indeterminate, suggesting the ultimate volitional rather than instinctive quality of these interactions. Acceptance of the greeting's form by no means obliged either participant to accept any particular outcome of the greeting itself; however, such mutual acquiescence to the protocols of greeting certainly conveyed each participant's apparent 
willingness to greet. Thus, the minimal social coordination of a completed greeting can serve to substantiate at least the possibility of further mutual interactions, while, conversely, an aborted greeting makes the present absence of mutuality between would-be greeters unmistakably obvious.

If indeed baboon greetings represent rituals in this constitutive sense, certain aspects of their behavioral content may also relate to the legitimizing role that Rappaport ascribes to ritual. That is, as ritualized gestures, the genital touching that sometimes occurs in greetings perhaps serves to enhance the truth value of whatever these males are "saying" to each other within the formally circumscribed context of greeting. Lacking articulate speech, and unable to swear oaths, perhaps male baboons make a gestural equivalent by literally placing their future reproductive success in the trust of another male. Such risky gestures may help to enhance whatever verity is presumed in the greeting because they impose a potential cost (risk of injury) on the presenting male (Zahavi, 1977). More specifically, the posterior present may provide the partner with an opportunity to "punish" the presenter for a previous failure to cooperate. Indeed, on rare occasions, we saw a presenting male cry out and run away while his greeting partner was touching him, although we were never able to see exactly what the touching male had done. In this regard, recall that even in modern law, taking an oath serves a similar purpose: it says, in effect, "I am willing to suffer punishment if you catch me in a lie" (R. Smuts, personal communication).

Of course, the parallel drawn here between aspects of human ritual and baboon greetings remains formal instead of substantive. Anthropologists have long recognized the distinction between "ritual" as the formal, stereotyped elements found in much of social behavior, and "rituals" as culturally constituted events in themselves (Rappaport, 1979a, p. 176). Although animals clearly have ritualized behavior in the first sense but lack rituals in a strict cultural sense, perhaps the baboon greetings discussed here represent something between the two. That is, the greetings may be utilizing ritual sexual behavior to constitute rituals of social coordination or dominance. As speculative as this appears, the human ethnographic record attests to reverse situations, in which culturally constituted rituals of truth and promise rest on less than arbitrarily chosen corporeal gestures. Meggitt (1965, p. 262) reports that, among Australian Aborigines, men from different communities demonstrate their willingness to support one another through a ritualized offering and grasping of the supplicant's penis. In Genesis (xxiv 9), Abraham's servant swears an oath to him while placing his hand under his master's "loins". Furthermore, the $O x$ ford English Dictionary suggests that the words "testify," "testimony," and "testicle" may all share a common root, "testis," which originally meant "witness." In other words, the formal parallels here suggest an evolutionary 
continuity between ritualized behavior and socially constituted rituals that demands closer attention from cultural anthropologists and sociobiologists alike.

\section{ACKNOWLEDGMENTS}

We thank Dorothy Cheney, Hans Kummer, Ronald Noë, Robert Smuts, Frans de Waal, Richard Wrangham, and an anonymous reviewer for valuable comments on the mansucript and acknowledge Irven DeVore and Roy Rappaport for inspiration. The research was supported by NSF grant BNS-83-03677. We are grateful to Jim Else of the Institute for Primate Research, Kenya, and Shirley Strum for logistical help in the field, and we thank the Government of Kenya for permission to conduct research. We also thank Karen Strier and Irven DeVore for organizing the symposium at which a version of this paper was presented. This is publication no. 106 of the Evolution of Human Behavior Program, University of Michigan.

\section{REFERENCES}

Abegglen, J. (1984). On Socialization in Hamadryas Baboons, Bucknell University Press, Lewisburg, Pennsylvania.

Altmann, J. (1974). Observational study of behaviour: Sampling methods. Behaviour 49: 227-267. Altmann, S. A., and Altmann, J. (1970). Baboon Ecology, University of Chicago Press, Chicago. Anthoney, T. R. (1968). The ontogeny of greeting, grooming, and sexual motor patterns in captive baboons (superspecies Papio cynocephalus). Behaviour 31: 358-372.

Anthoney, T. R. (1975). Evolution of social structure in baboons, Ph.D. dissertation, Pritzker School of Medicine, Chicago.

Axelrod, R. (1984). The Evolution of Cooperation, Basic Books, New York.

Berkovitch, F. (1986). Male rank and reproductive activity in savanna baboons. Int. J. Primatol. 7: $533-550$.

Bygott, D. (1974). Agonistic behaviour and dominance in wild chimpanzees, Ph.D. dissertation, University of Cambridge, Cambridge.

DeVore, I. (1962). The social behavior and organization of baboon troops, Ph.D. dissertation, University of Chicago, Chicago.

Estes, R. D. (1969). Territorial behavior of the wildebeest (Connochaetes taurinus Burchell, 1823). Z. Tierpsychol. 26: 284-370.

Goffman, E. (1971). Relations in Public, Basic Books: New York.

Goodall, J. (1986). The Chimpanzees of Gombe, Harvard University Press, Cambridge.

Harding, R. S. O. (1980). Agonism, ranking, and the social behavior of adult male baboons. Am. J. Phys. Anthrop. 53: 203-216.

Hausfater, G. (1975). Dominance and reproduction in baboons. Contributions to Primatology 7: $1-150$.

Hausfater, G., and Takacs, D. (1987). Structure and function of hindquarter presentations in yellow baboons (Papio cynocephalus). Ethology 74: 297-319.

Huxley, J. (1966). Discussion on ritualization of behavior in animals and man. Phil. Trans. R. Soc. Lond. B. 251: 249-271. 
Kummer, H. (1968). Social Organization in Hamadryas Baboons, University of Chicago Press, Chicago.

Kummer, H. (1975). Rules of dyad and group formation among captive gelada baboons (Theropithecus gelada). In Kondo, S., Kawai, M., Ehara, A., and Kawamura, S. (eds.), Proceedings of the Symposia of the 5th Congress of the International Primatological Society, Nagoya, 1974, Japan Science Press, Tokyo, pp. 129-159.

Kummer, H. (1984). From laboratory to desert and back: A social system of hamadryas baboons. Anim. Behav. 32: 965-971.

Manzolillo, D. (1982). Intertroop transfer by adult male Papio anubis, Ph.D. dissertation, University of California, Los Angeles.

Meggitt, M. J. (1965). The Desert People: A Study of the Walbiri of Central Australia, University of Chicago Press, Chicago.

Packer, C. (1977). Reciprocal altruism in Papio anubis. Nature, Lond. 265: 441-443.

Packer, C. (1979a). Inter-troop transfer and inbreeding avoidance in Papio anubis. Anim. Behav. 27: 1-36.

Packer, C. (1979b). Male dominance and reproductive activity in Papio anubis. Anim. Behav. 27: $37-46$.

Pelaez, F. (1982). Greeting movements among adult males in a colony of baboons: Papio hamadryas, Papio cynocephalus, and their hybrids. Primates 23: 233-244.

Popp, J. L., (1978). Male baboons and evolutionary principles, Ph.D. dissertation, Harvard University.

Ransom, T. W. (1981). Beach Troop of the Gombe, Bucknell University Press, Lewisburg, Pennsylvania.

Rappaport, R. A. (1979a). The obvious aspects of ritual. In Rappaport, R. A. (ed.), Ecology, Meaning, and Religion, North Atlantic Books, Berkeley, California, pp. 173-221.

Rappaport, R. A. (1979b). Sanctity and lies in evolution. In Rappaport, R. A. (ed.), Ecology, Meaning, and Religion, North Atlantic Books, Berkeley, California, pp. 223-246.

Saayman, G. S. (1971). Behavior of the adult males in a troop of free-ranging chacma baboons. Folia Primatol. 16: 161-178.

Sapolsky, R. M. (1983). Endocrine aspects of social instability in the olive baboon (Papio anubis). Am. J. Primatol. 5: 365-379.

Scheflen, A. E. (1967). On the structuring of human communication. Am. Behav. Scient. 10: 8-12.

Scott, L. M. (1984). Reproductive behavior of adolescent female baboons (Papio anubis) in Kenya. In Small, M. F. (ed.), Female Primates: Studies by Women Primatologists, Alan R. Liss, New York, pp. 77-100.

Sigg, H. (1981). Entwicklung von Zweierbeziehungen bei jungadulten Rhesusaffenmännchen und ihre Beeinflussung durch Psychopharmaka. In Blösch, M. (ed.), Erlander Forschungen, Series B, Vol. 11: Die Beeinflussung angeborener Verhaltensweisen durch neurotrope Substanzen, Erlangen-Nürnberg, Universitätsbund Erlangen-Nürnberg, pp. 78-87.

Sigg, H., and Stolba, A. (1981). Home range and daily march in a hamadryas baboon troop. Folia Primatol. 36: 40-75.

Smith, W. J. (1977). The Behavior of Communicating: An Ethological Approach, Harvard University Press, Cambridge, Massachusetts.

Smuts, B. B. (1982). Special relationships between adult male and female olive baboons ( $\mathrm{Pa}-$ pio anubis), $\mathrm{Ph} . \mathrm{D}$. dissertation, Stanford University.

Smuts, B. B. (1983a). Dynamics of 'special relationships' between adult male and female olive baboons. In Hinde, R. A. (ed.), Primate Social Relationships, Blackwell Scientific Publications, Oxford, pp. 112-116.

Smuts, B. B. (1983b). Special relationships between adult male and female olive baboons: Selective advantages. In Hinde, R. A. (ed.), Primate Social Relationships, Blackwell Scientific Publications, Oxford, pp. 262-266.

Smuts, B. B. (1985). Sex and Friendship in Baboons, Aldine de Gruyter, Hawthorne, New York.

Strum, S. C. (1982). Agonistic dominance in male baboons: An alternative view. Int. J. Primatol. 3: $175-202$.

Strum, S. C. (1983). Use of females by male olive baboons (Papio anubis). Am. J. Primatol. 5: 93-109. 
Strum, S. C. (1984). Why male baboons use infants. In Taub, D. M. (ed.), Primate Paternalism, Van Nostrand Reinhold, New York, pp. 146-185.

Strum, S. C. (1987). Almost Human, Random House, New York.

Sugawara, K. (1979). Sociological study of a wild group of hybrid baboons between Papio anubis and Papio hamadryas in the Awash Valley of Ethiopia. Primates 20: 21-56.

Trivers, R. L. (1971). The evolution of reciprocal altruism. Q. Rev. Biol. 46: 35-57.

de Waal, F. B. M. (1982). Chimpanzee Politics: Power and Sex among Apes, Harper and Row, New York.

de Waal, F. B. M. (1986). The integration of dominance and social bonding in primates. $Q$. Rev. Biol. 61: 459-479.

Zahavi, A. (1977). The testing of a bond. Anim. Behav. 25: 246-247. 